\title{
Türkçede Göz Sözcüğünün Deyimler Aracılığıyla Kavramsallaştırılması*
}

\author{
Melike Baş \\ Amasya Üniversitesi, Eğitim Fakültesi, İngiliz Dili Eğitimi Bölümü, Akbilek Mah. Hakimiyet \\ cad. No:4/3 Amasya \\ melike.bas@amasya.edu.tr
}

(Gönderilme tarihi 26 Ağustos 2016; kabul edilme tarihi 19 Aralı 2016)

\begin{abstract}
ÖZ: Bu çalışma, Türkçe deyimlerde 'göz' sözcüğünü bilişsel dilbilimsel bir açıdan inceleyip, göz sözcüğ̈̈nün Türkçe konuşan bireylerde olușturduğu bilişsel şemaları ortaya çıkarmayı ve 'göz'e ait kültürel bir model önerisinde bulunmayı amaçlamaktadır. Çalışmanın veri tabanı çeşitli deyimler sözlükleri taranarak elde edilen ve göz sözcüğü içeren deyimlerden oluşmaktadır. Deyimler ve tanımları incelenerek soyut kavramların ifadelerindeki değişmeceli kullanımlar saptanmış ve bu deyimlerin altında yatan kavramsal eğretilemeler ve düzdeğişmeceler Kavramsal Eğretileme Kuramı (Lakoff ve Johnson, 1980; Kövecses, 2000) çerçevesinde tespit edilip açıklanmıştır. Bulgular, 'göz'ün çoğunlukla GÖZÜN İŞLEVİ YERİNE GÖZ olarak kavramsallaştığını göstermektedir. Bunun dışında, göz sözcüğünün, zihinsel yetilerin (hatırlama, niyet), duyguların (sevgi, üzüntü), kişilik özelliklerinin (hırs, saflık), fiziksel durumların (ölüm, zaman) ve kültürel ögelerin (nazar, beddua) kavramsallaşmasında kullanıldığını ortaya koymaktadır. Çalışma, dil, beden, biliş ve kültür arasındaki yakın ilişkiye Türkçe üzerinden destek sağlamaktadır.
\end{abstract}

Anahtar sözcükler: bedenleşmiş biliş, göz, eğretileme, düzdeğişmece, deyim

\section{Conceptualizations of the Eye in Turkish Idioms}

ABSTRACT: This study aims at investigating the word 'eye' in Turkish idioms from a cognitive linguistic perspective to reveal Turkish speakers' cognitive schemas of the 'eye', and to propose a cultural model relating the 'eye'. The database is composed of idioms containing the word 'eye' compiled from several monolingual dictionaries of Turkish idioms. Idioms and their definitions are analyzed in terms of their figurative use of abstract concepts. The conceptual metaphors and metonymies were identified on the basis of the Conceptual Metaphor Theory (Lakoff \& Johnson, 1980; Kövecses, 2000). The findings reveal that the 'eye' is generally conceptualized as EYE FOR THE FUNCTION OF EYE. Additionally, it is

$\mathrm{Bu}$ çalışma, 30. Ulusal Dilbilim Kurultayı 2016 Mayıs'ta sunulan bildirinin genişletilmiş biçimidir.

Dilbilim Araştırmaları Dergisi, 2016/2, 17-37.

(C) 2016 Boğaziçi Üniversitesi Yayınevi, İstanbul. 
used in the conceptualizations of mental faculties (remembering, intention), emotions (love, sadness), personal characteristics (greed, naiveté), physical states (time, death), and cultural elements (evil eye, curses). The study provides further support for the interaction among language, body, cognition and culture in Turkish.

Key words: embodiment, eye, metaphor, metonymy, idioms

\section{Giriş}

Bilişsel Dilbilim, bedenleşmiş biliş (embodiment) ilkesine bağlı olarak, zihni ve bilişi bedensel deneyimlerin aracılığıyla incelemekte ve dil, duygu, düşünce gibi soyut hedef alanlarını, insan bedeni gibi somut kaynak alanlara dayanarak incelemektedir. Deneyimlerimiz, sahip olduğumuz bedenlerimizin doğası ve nörolojik yapısı tarafından kısmen biçimlenmekte ve bu durumun biliş üzerinde etkileri olmaktadır. Bu sebeple "bizler sadece algıladığımız ve tasavvur ettiğimiz şeyler üzerine düşünebilir ve konuşabiliriz"1 (Evans ve Green, 2006, s. 46). Bu görüşten hareketle, diyebiliriz ki insan bedeni soyut kavramların deneyimlenmesinde ve kavramsallaştırılmasında önemli bir rol oynamaktadır ve insan zihni bedenleşmiş deneyimlerin izlerini taşımaktadır. Bu bağlamda, bu çalışma, bir beden bölümü olan gözün kalıplaşmış ifadeler olan deyimler vasıtasıyla nasıl kavramsallaştığı ve ne tür değişmeceli ifadelerde kullanıldığını Bilişsel Dilbilimin Kavramsal Eğretileme Kuramı açısından inceleyip, gözün Türkçe konuşan bireylerde oluşturduğu bilişsel şemaları ortaya çıkarmayı ve göze ait kültürel bir model önerisinde bulunmayı amaçlamaktadır.

Son yıllarda farklı dillerde yapılan çalışmalar, toplumsal değerler ve kültürün etkisiyle, her dilin bedenle ve beden bölümleriyle ilgili kendine özgü bilişsel modeller oluşturduğunu ortaya koymuştur (Maalej ve Yu, 2011; Sharifian, Dirven, Yu ve Niemeier, 2008). Bu durum, insanın bedensel deneyimlerinin bilişe aracılık etmede tek başına yeterli olmadığını ve tarihsel ve kültürel bağlamların bedenleşmiş biliş ilkesini tamamlayan etkenler olduğunu göstermektedir. Diğer bir ifadeyle, biliş sadece bireylerin değil, kültürel toplulukların da bir özelliği olarak karşımıza çıkmaktadır. Sharifian'ın kültürel biliş olarak da adlandırdığı bu kolektif biliş, bilişsel ağlar kuran bir topluluğun üyeleri arasındaki karşılıklı etkileşimler sonucu ortaya çıkan bir olgu olarak görülmektedir (Sharifian, 2008, 2009, 2011). Kültürel biliş, bu topluluğun üyelerinin zihinlerinde heterojen bir şekilde dağılmaktadır ve zaman ve uzam içinde yeniden müzakere edildiğinden dinamik bir yapı göstermektedir (Sharifian, 2008, 2009, 2011). Bu noktada kavramsallaştırmalar ve dil, kültürel bilişin iki ayrılmaz yönünü oluşturmaktadır.

1 Özgün metinden Türkçeye çeviriler yazara aittir. 
Sharifian'ın ortaya attığı görüşten yola çıkılarak, denilebilir ki bedenin bilişsel yaşantımızdaki rolü ne olursa olsun bedene ait kavramsallaştırmalar bir kültürden diğerine farklılıklar gösterebilir ve beden, kültürel deneyimlerimiz için kavramsal bir kaynak olarak görev yapmaktadır (Sharifian, 2008). Bu açıdan, bedenin önemli bir parçası olan 'göz'ün nasıl kavramsallaştığını ortaya çıkarmak, görsel algıya ait deneyimlerin dilde, dolayısıyla da zihinlerde nasıl kodlandığını tespit etmek açısından önem taşımaktadır.

'Göz'ün nasıl kavramsallaştı̆̆1 üzerine çeşitli dillerde çalışmalar bulunmaktadır (örn., Yu, 2002, 2004; Maalej, 2011; Occhi, 2011; Sharifian, 2011, 2012; Siahaan, 2011). Bu çalışmalardan Yu (2004), İngilizce ve Çince üzerine yaptığı karşılaştırmalı çalışmasında, her iki dilde göz sözcüğünün "algılama yerine algısal organ" ve "düşünme, anlama ve bilme görmedir" olarak kavramsallaştığını gözlemlemiştir. Gözün ayrıca Çincede kaşlarla birlikte öfke, kıskançlık, endişe, küçümseme gibi duygusal durumların göstergeleri olduğu tespit edilmiştir (Yu, 2002).

Modern Farsça'da 'göz', genellikle duyguların merkezi olarak kodlanmakta ve düşünme ve bilme gibi bilişsel yetiler, sezgiler, sevgi ve kıskançlık duyguları, hırs ve haset gibi kişilik özelliklerine dair kavramsallaştırmalarda kullanılmaktadır (Sharifian, 2012). Tunus Arapçasında göz (3ayn) sözcüğünün zihinsel yetiler (bilme, anlama, düşünme, konuşma), fiziksel durumlar (uyku, ölüm, zaman), duygu (sevgi, arzu, öfke, suçluluk, haset), karakter özellikleri (hırs, açgözlülük, saflık, arsızlık), ve kültürel değerlerin (sayg1, misafirperverlik) kavramsallaştırılmasında kültürel bir model oluşturduğu tespit edilmiştir (Maalej, 2011).

Türkçe alanyazında, göz sözcüğü üzerine bilişsel dilbilimsel bir çalışmaya rastlanmamaktadır. Buna bağlı olarak, bu çalışma alandaki boşluğu doldurmayı ve içinde göz sözcüğü geçen deyimlerden yola çıkarak Türkçede 'göz'e dair kavramsal eğretilemeleri ve düzdeğişmeceleri ortaya çıkarmayı amaçlamaktadır. Çalışmadan elde edilecek bulgular, diğer dillerde yapılmış çalışmalarla benzerlikleri ve farklılıkları ortaya koyması açısından önem taşımaktadır.

\subsection{Kavramsal Ĕgretileme ve Düzdeğişmece}

Kavramsal Eğretileme Kuramı, bilişsel dilbilimin en eski kuramsal çerçevelerinden biridir ve bilişsel sistemimizin doğası gereği eğretilemesel bir yapıya sahip olduğu savından yola çıkmaktadır (Lakoff ve Johnson, 1980; 1999). Bu kurama göre zihnimizdeki pek çok kavram başka kavramlar yoluyla tecrübe edilmekte ve anlaşılmaktadır. Örneğin, YUKARI kavramı, bir bedene sahip olmamızdan ve bedenlerimizin dikey pozisyonda durmasindan kaynaklanmaktadır. 
Kavramsal Eğretileme Kuramı, eğretileme ve düzdeğişmeceyi kavramsal izdüşüme (conceptual projection) yol açan bilişsel mekanizmalar olarak tanımlamaktadır, dolayısıyla eğretileme ve düzdeğişmece sadece dile ait söz sanatları değil, düşünce sistemimizin ve kavramsallaştırmalarımızın temel parçalarıdır. Eğretilemeler ve düzdeğişmeceler kültürel ve bilişsel modellerin hem göstergeleridir hem de bu modellerin oluşumlarında rol oynamaktadırlar (Kövecses, 2000). Bu bakımdan bilişsel dilbilimsel çalışmalarda önemli bir yere sahiptirler. Bu bilişsel mekanizmaların nasıl işlediğini gözlemleme imkanı sağladı̆̆ından dil, kavram sistemimizi anlamada temel delil kaynaklarından biridir (Lakoff ve Johnson, 1980).

Kavramsal eğretileme, iki farklı üst deneyim alanı arasındaki eşleşmeleri (mappings) kapsar; yani hedef alan, kaynak alan vasıtasıyla kısmen yorumlanıp anlaşılır. Eğretilemesel eşleşmeler her zaman tekyönlüdür, yani eşleşme kaynak alanın hedef alana izdüşümü ile oluşur. Kavramsal eğretilemeler $A B$ 'dir (A is B) olarak formüle edilmektedir (Barcelona, 2000; Kövecses, 2010). Lakoff ve Johnson (1980) kavramsal eğretilemeleri üç kategori altında incelemektedirler. $\mathrm{Bu}$ kategorilerden yapısal (structural) eğretilemeler, soyut bir kavramın somut bir kavram vasıtasıyla yapılandığı eğretilemeleri kapsamaktadır (Kövecses, 2010, p.37). Örneğin, TARTIŞMA SAVAŞTIR veya ZAMAN HAREKETTİR eğretilemelerinde soyut hedef alanlar TARTIŞMA ve ZAMAN, somut kaynak alanlar SAVAŞ ve HAREKET üzerinden anlamlandırılmaktadır. Varlık (ontological) eğretilemeleri soyut deneyimlerimizin nesneler, tözler, kaplar gibi varlıklar olarak düşünüldüğü eğretilemeleri kapsamaktadır. ZİHIN MAKİNEDİR eğretilemesinde olduğu gibi, zihin ve zihni tecrübeler, fiziksel özelliklere sahip bir varlık olarak kavramsallaşmaktadır (Lakoff ve Johnson, 1980).

Yönelim (orientational) eğretilemeleri, aşağı/yukarı, içeri/dışarı, ön/arka, merkez/çevre gibi imge şemalarıyla uzamsal yönelimler içeren eğretilemelerdir. İmge şemaları, duyumsal, algısal ve motor deneyimlerden kaynaklanan şematik geştaltlardır (Johnson, 1987). Bu temel fiziksel deneyimler eğretilemesel bir şekilde soyut kavramların şekillenmesini sağladığından imge şeması eğretilemeleri olarak da tanımlanır (Kövecses, 2010, p.42). Bu eğretileme türü MUTLULUK YUKARDADIR / ÜZÜNTÜ AŞAĞIDADIR eğretilemelerinde olduğu gibi sahip olduğumuz bedenlerimizin fiziksel çevrede işleyişlerinden kaynaklanmaktadır ve kültürel tecrübelerimiz tarafından şekillenmektedir (Lakoff ve Johnson, 1980).

Kavramsal düzdeğişmece ise aynı üst deneyim alanının farklı alt alanları arasındaki eşleşmeleri kapsamaktadır, yani kaynak alan zihinsel olarak hedef alanı harekete geçirmektedir (Barcelona, 1997; 2000). Bu açıdan, düzdeğişmece, eğretilemeden farklı olarak temsil etme ilişkisini yansıtmaktadır ve genellikle $A$ yerine $B$ (A stands for B) olarak formüle edilmektedir. Düzdeğişmece, bedensel deneyimlerle doğrudan bağlantılı olduğu için 
eğretilemelere göre daha temel bilişsel bir olgudur ve birçok durumda eğretilemelerin ortaya çıkmasında etkili olmaktadır (Panther ve Radden, 1999; Barcelona, 2003; Kövecses, 2010). Düzdeğişmece, BÜTÜN YERİNE PARÇA, PARÇA YERINE BÜTÜN ve PARÇA YERINE PARÇA olarak üç genel kategoride incelenmektedir ve her bir kategori içerisinde farklı alt düzdeğişmece türleri yer almaktadır (Kövecses ve Radden, 1998; Kövecses, 2010; Barcelona, 2011).

Kavramsal eğretileme ve düzdeğişmece çoğu zaman karmaşık etkileşim ve birleşmeler sonucu birbiriyle iç içe geçmiş durumdadırlar. Bu sebeple bu iki bilişsel mekanizma arasında her zaman net bir ayrım yapmak zordur ve eşleşme süreci doğrusunun üzerinde farklı noktalarda konumlanabilirler (Barcelona, 2000, s. 16). Eğretileme ve düzdeğişmece arasındaki bu kavramsal etkileşim örüntüsü düzeğretilemece (metaphtonomy) olarak adlandırılmaktadır (Goossens, 1995). Düzeğretilemeceler genellikle iki durumda ortaya çıkmaktadır. Buna göre, bazı düzdeğişmeceler eğretilemelerin oluşmasında kavramsal bir temel sağlamaktadır veya bazı eğretilemeler düzdeğişmecelerin ortaya çıkmasında etken olabilmektedir. Örneğin, 'dişini sıkmak' deyimi, insanların fiziksel acıyı bastırmak için dişlerini sıkma eylemine dayandığından düzdeğişmecesel bir temele sahiptir. Bu deyim, 'sı1kıntıya katlanmak, olumsuz duygu ve düşünceleri bastırmak' anlamında kullanıldığında eğretilemesel bir anlam kazanmaktadır. Bu açıdan bu deyim düzdeğişmecenin kavramsal olarak güdülediği bir eğretileme olarak tanımlanmaktadır.

\section{Veri Toplama ve Çözümleme Yöntemi}

Çalışmanın evreni, 12 farklı deyimler sözlüğü taranarak elde edilen ve içinde göz sözcüğü geçen 374 deyimden oluşmaktadır. Deyimler, insanların deneyimlerini, dünya görüşlerini, yaşam biçimlerini yansıtan topluma ait dil ürünleridir, dolayısıyla kültürel ve bilişsel kavramsallaştırmaları ortaya çıkarmada önemli kaynaklardır. Kövecses'in de belirttiği gibi, deyimlerin büyük bir çoğunluğu sadece dil meselesi olmaktan ziyade kavramsal sistemimizin ürünleridir. Bir deyimin anlamı kavramsal sistemimizin içinde yer alan genel dünya bilgisinden doğmaktadır (2010, s. 233). Bu sebeple kalıplaşmış ifadeler olan deyimler arasından göz sözcüğü içerenler çalışmanın veri tabanı olarak tercih edilmiştir.

Sözlüklerden derlenen 'göz' deyimlerinin tanımları tek tek incelenerek değişmeceli kullanımları saptanmış ve ortak özelliklerine göre gruplanmıştır. Deyimlerde ifade edilen sevinç, üzüntü, korku gibi farklı duygu türlerinin tespitinde Baş'ın (2015) geliştirdiği Duygu Sınıflaması Modeli kullanılmıştır. Deyimlerin altında yatan kavramsal eğretileme ve düzdeğişmeceler, Lakoff ve Johnson (1980) tarafından ortaya atılan ve Sweetser (1990) ve Kövecses (2000) 
tarafından geliştirilen Kavramsal Eğretileme Kuramı çerçevesinde tespit edilip açıklanmıştır. Çalışmanın amacı, bir dış organ vasıtasıyla bedenleşmiş bilişi teyit etmek ve 'göz' deneyiminin genel bir görünüşünü ortaya koymak olduğundan çalışma nitel bir özellik taşımaktadır. $\mathrm{Bu}$ sebeple deyimlerin ve bilişsel yapıların sayısal dağılımlarının hesaplanması çalışmanın amaçları dışında bırakılmıştır.

\section{Siniflandırma}

Verilerin çözümlemesi ile elde edilen bulgular altı temel düzdeğişmecesel kategori altında sınıflandırılıp incelenmiştir: Gözün İşlevleri Yerine Göz, Zihinsel Yetilerin Kavramsallaştırılmasında Göz, Duyguların Kavramsallaştırılmasında Göz, Ö̈zelliklerinin Kavramsallaştırılmasında Göz, Fiziksel Durumların Kavramsallaştııılmasında Göz ve Kültürel Ögelerin Kavramsallaştırılmasında Göz. Bu altı kategori içerisinde yer alan kavramsal eğretilemeler ve düzdeğişmeceler, örnek deyimlerle birlikte açıklanmıştır.

\subsection{Gözün Isslevleri Yerine Göz}

Görme organı olarak gözler ve gözlerle ilişkilendirilen davranışlar ve işlevler aynı kavramsal deneyim alanı içinde yer alırlar. Gözlerin, bu işlevler veya davranışların kavramsal olarak yerine geçtiği durumda GÖZÜN İŞLEVI YERİNE GÖZ üst düzdeğişmecesi ortaya çıkmaktadır. Barcelona'ya göre, bakma, göz kırpma ve (üzüntü gibi sebepler nedeniyle) ağlama göze ait davranışlar olarak değerlendirilir ve gözler düzdeğişmecesel bir şekilde, insanlar tarafından kontrol edilebilen bu davranışların yerine geçmektedir (1997, s. 39). Göze ait davranışlar, gözün işlevlerinden biri olduğu için GÖZE AIIT DAVRANIŞLAR YERİNE GÖZ (EYES FOR OCULAR BEHAVIOR) düzdeğişmecesi, bir üst düzdeğişmece olan GÖZÜN İşLEVİ YERİNE GÖZ'ün (EYES FOR FUNCTION OF EYES) özel bir durumu olarak görülmektedir (Barcelona, 1997, s. 39).

Veri tabanında bulunan deyimlerden, 'göz' yoluyla iletişim kurmayı ifade eden göz etmek, göz kırpmak, kaş göz etmek/işareti yapmak, karanlıkta göz kırpmak deyimleri, ağlamayı ifade eden gözü sulu/yaşl, gözleri nemlenmek, iki gözü iki çeşme deyimleri ve bakma eylemi ifadeleri için kullanılan göz atmak, göz süzmek, göz gezdirmek, göz hapsine almak, gözü takllmak, gözden geçirmek, göz banyosu, göz eğlendirmek, yan gözle bakmak, gözlerini dikmek, gözlerini kaçırmak, göz göze gelmek, gibi deyimler GÖZE AİT DAVRANIŞLAR YERINE GÖZ düzdeğişmecesine örnek oluşturmaktadır. Ayrıca, bu deyimlerden 'göz' aracıllğıyla iletişim kurmayı ifade eden 
deyimlerin altında ILETIŞSiM KURMAK GÖRMEKTİR kavramsal eğretilemesi yatmaktadır.

Diğer taraftan, görme, gözyaşı dökme, istemsiz göz kırpma kişiler tarafindan tamamen kontrol edilemediği için, algısal, fizyolojik veya psikolojik süreçler veya uyarana verilen bir tepki olarak değerlendirilmekte ve gözün işlevleri arasında değerlendirilmektedir (Barcelona, 1997, s. 39). Gözün icra ettiği fizyolojik işlevlerle düzdeğişmecesel olarak eşleşmesi ve kavramsal olarak bu işlevleri vurgulaması, GÖZÜN İŞLEVİ YERİNE GÖZ düzdeğişmecesini doğurmaktadır (Şekil 1).

Şekil 1. GÖZÜN IŞLEVI YERINE GÖZ kavramsal düzdeğişmecesi

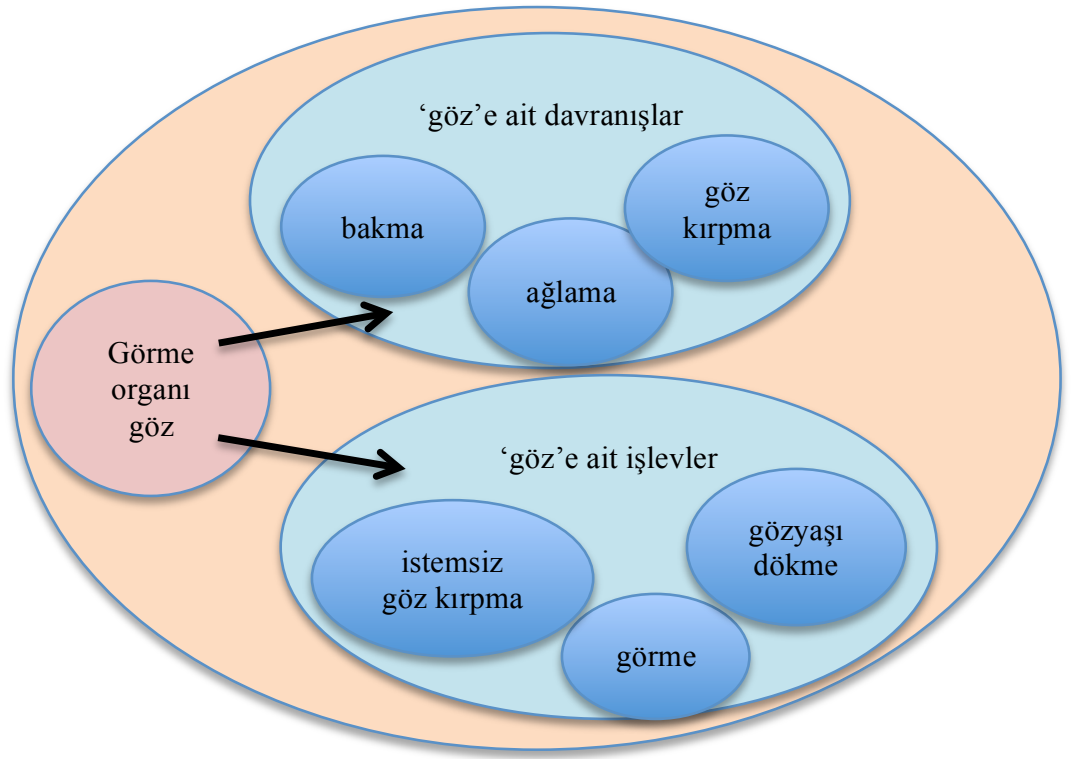

Veri tabanı incelendiğinde, bulgular, gözün, görmeyi sağlayan bir duyu organı olarak fizyolojik işlevini ön plana çıkartan ALGI YERİNE ALGISAL ORGAN üst düzdeğişmecesi altında GÖRME YERINNE GÖZ olarak kavramsallaştığını göstermektedir. Bu deyimlerden bazıları, gözden uzaklaşmak, gözü hiçbir şey görmemek, göz alabildiğine, göz derya seyir bedava, göz önü, çıplak gözle, göz kapamak, gözünün önünü görmemek, gözü keskin, gözü önünde, gözü(ne) ilişmek, göz gözü görmemek, gözüne dayamak, gözden kaçırmak, gözden kaybetmek/kaybolmak, gözü kaymak, vs. olarak listelenebilir. 


\subsection{Zihinsel Yetilerin Kavramsallaștırılmasında Göz}

ZİHIN BEDENDİR (MIND IS BODY) üst kavramsal eğretilemesi, fiziksel algılamaya ait sözcüklerle zeka ve bilgiye ait sözcükler arasında yakın bir ilişkiden ortaya çıkmaktadır. Gözler diş dünyaya açılan pencerelerdir; deneyimlerimizin ve öğrendiklerimizin çoğu gözlerimizden gelir. Yapılan çalışmalarda saptanan örnekler, ZİHİN BEDENDİR eğretilemesinin alt versiyonları olan DÜŞÜNMEK, BİLMEK veya ANLAMAK GÖRMEKTİR kavramsal eğretilemelerini ortaya koymaktadır (Lakoff ve Johnson, 1999; Radden, 1996; Sweetser, 1990; Yu, 2003). Yu (2004, s. 669), bu alt eğretilemelerin birbiriyle ilişkili iki eşleşmeyi gerektirdiğini ifade etmektedir: "ZİHINSEL BECERİ GÖRME DUYUSUDUR (MENTAL CAPABILITY IS EYESIGHT) ve ZİHINSEL YETERLIK BAKIŞTIR (MENTAL CAPACITY IS EYESHOT)."

Yapılan incelemede zihinsel yetiler kategorisi altında dikkat etme, deneyim kazanma/öğrenme, değerlendirme/karar verme, hatırlama/zihinde canlandırma/unutma, kontrol etme/denetim ve düşünce/niyet etme kavramsal alanları tespit edilmiştir. İnsanlar herhangi bir sebeple gözlerini kapadıklarında göremezler; gözlerini açtıklarında ise görebilirler. Bu bedensel ve algısal deneyim, göz deyimlerindeki zihinsel işlevlere ait eğretilemelerin deneyimsel temelini sağlamaktadır. Diğer bir ifadeyle, 'zihinsel işlevler' kavram alanı düzdeğişmecenin temelini oluşturduğu 'görsel algı' kavram alanı aracılığıyla anlaşılmaktadır. $\mathrm{Bu}$ bakımdan, aynı algısal deneyim alanı içerisindeki düzdeğişmecesel aktarım, zihinsel yetilerle ilgili tespit edilen ZİHİNSEL IŞLEV ALGIDIR (MENTAL FUNCTION IS PERCEPTION) üst eğretilemesinin temelini oluşturmaktadır. Düzeğretilemece olarak da adlandırabileceğimiz kompleks yapıdaki bu eğretileme Şekil 2'de sunulmaktadir:

Şekil 2. ZIHHINSEL İSLEV ALGIDIR kavramsal ĕgretilemesi

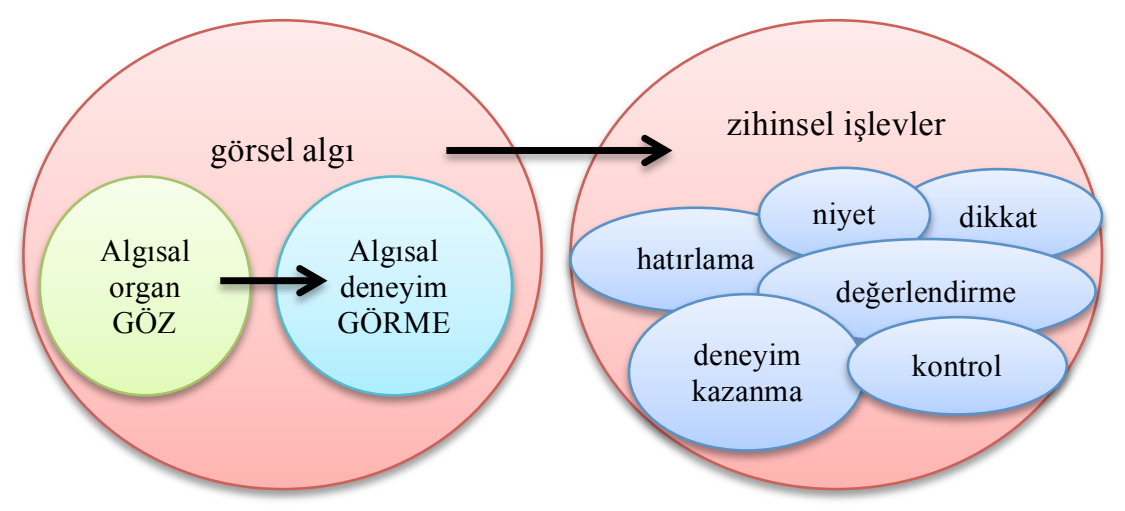




\subsubsection{DIKKAT ETME YERINE GÖZ kavramsal düzdeğişmecesi}

Gözlerimiz genellikle dikkatimizin üzerinde olduğu yere doğru yönelir. Bu bedensel deneyimimizin temelini oluşturduğu ad aktarımı karmaşık yapıdaki DİKKAT ETMEK GÖRMEKTİR eğretilemesini doğurmaktadır. Veri tabanında tespit edilen deyimlerden gözünü dört açmak, gözünden kaçmak/kaçırmamak, gözü (birinin, bir şeyin) üzerinde olmak, göz kesilmek, göze çarpmak, gözlüye gizli olmamak, dört gözle bakmak, deyimleri bu kategori içinde değerlendirilebilir.

\subsubsection{KONTROL/DENETIM YERINE GÖZ kavramsal düzdeğişmecesi}

Sweetser'a göre (1990, s. 32), koruma veya kontrol altında tutma genellikle kişinin gözüyle kontrol edilen nesneye bakması veya gözüyle izlemesini içermekte ve KONTROL ETMEK GÖRMEKTİR, DENETLEMEK GÖRMEKTİR ve KORUMAK GÖRMEKTİR eğretilemelerini ortaya çıkarmaktadır. Bu alanlar arasındaki kavramsal eşleşme Türkçe deyimlerde gözünü üstünden ayırmamak, göz(ünün) önünde olmak, gözünün önünden ayırmamak, göz kulak olmak deyimlerinde ifade bulmaktadır. Ayrıca, deyimlerde geçen ÖN imge şeması, gözün ön kısmında bulunan bir nesnenin doğrudan görüş açısına girmesinden dolayı ÖNEM VERİLEN/DENETLENEN ŞEY GÖZÜN ÖNÜNDEDİR yönelim eğretilemesinin kavramsal temelini oluşturmaktadır.

\subsubsection{DENEYIM KAZANMA / ÖĞRENME YERINE GÖZ kavramsal düzdeğişmecesi}

Veri tabanında tespit edilen gözü (gözleri) açılmak, Arap'ın gözü açıldı, maymun gözünü açtı, gözünü (gözlerini) açmak, gözlerinin bağını açmak deyimleri bireyin yaşadığı olaydan ders aldığını, deneyim kazandığını, yeni bir şey öğrendiğini ve bilinçlendiğini ifade etmektedir. Ayrıca, deneyimsizlik ifadelerinde kullanılan gözü bağll ve gözü küllü deyimleri gözün kapalı olması veya net görememesi ile kişinin deneyimsiz olması, iyi ve kötüyü ayırt edememesi arasında bir ilişki kurmaktadır. Daha önceden kapalı olan gözün açılması, dolayısıyla görmeye başlama DENEYIM KAZANMAK / ÖĞRENMEK GÖRMEYE BAŞLAMAKTIR eğretilemesini doğurmaktadır. 


\subsubsection{DE ĞERLENDIRME / KARAR VERME YERINE GÖZ kavramsal düzdeğişmecesi}

Görme sonucu yapılan yargılamalar, değerlendirmeler ve bunun sonucunda verilen kararlar değişmeceli olarak göz kararı, gözüyle (gözleriyle) tartmak, göz terazisi, deyimlerinde ifade edilmektedir. Bu bakımdan 'göz' karar vermede bir referans noktası olarak algılanmaktadır. Ayrıca, göz önünde tutmak (bulundurmak), göz önüne almak deyimlerinde bir durumu değerlendirmek ve bu deyimlerle zit anlamlı olarak gereken önemin verilmediği ve değerlendirmeye dâhil edilmediğini ifade eden göz ardl etmek deyimi, ÖN/ARKA imge şemasının izdüşümü olarak ÖNEM VERILLEN ŞEY GÖZÜN ÖNÜNDEDIR imge eğretilemesini doğurmaktadır. Dolayısıyla, bir şeyin gözün ön ve arka kısmında yer alması o şeyin önem derecesini belirtmekte ve önem verilen şeyler gözün ön kısmı ile ilişkilendirilirken önem verilmeyen şeyler gözün arka kısmı ile ilişkilendirilmektedir.

\subsubsection{HATIRLAMA / ZIHINDE CANLANDIRMA / UNUTMA YERINE GÖZ kavramsal düzdeğişmecesi}

Gözünün önünden geçmek, gözünün önüne gelmek/getirmek, gözü ısırmak, göz aşinalığı, gözünün önünden gitmemek gibi deyimlerde kişinin zihninde canlandırdığı, tasarladığı, hatırladığı veya unutamadığı durumlar ifade edilmekteyken, bir șeyin unutulması ve yok olması gözlerden silinmek deyimi ile ifade edilmektedir. Deyimler ÖN/ARKA imge şemasına dayanmakta ve gözün ön kısmı ile imgeleme arasında kurulan ilişki HATIRLAMAK/ZIHINDE CANLANDIRMAK GÖRMEKTIR yönelim eğretilemesi ve GÖZLER HAFIZA İÇîN BİR KAPTIR varlık eğretilemesi olarak kavramsallaşmaktadır.

\subsubsection{DÜŞÜNCE / NIYET YERINNE GÖZ kavramsal düzdeğişmecesi}

Zihinsel bir işlem olan düşünmenin fiziksel bir alan olan görme vasıtasıyla kavramsallaştığı bilişsel dilbilimciler tarafından sıklıkla dile getirilmektedir (Lakoff ve Johnson, 1980). Nasıl düşündüğümüz ile nasıl baktığımız arasında kurulan ilişki eğri/kötü gözle bakmak, iyi gözle bakmak, gözlerinden okumak, boş gözle bakmak, ne gözle bakmak deyimlerinde ifade bulmaktadır ve GÖZ NIYETIMIZİ/DÜS̈ÜNCEMIZİ YANSITAN BİR AYNADIR eğretilemesini ortaya çıkarmaktadır.

Diğer yandan, göz bă̆gl, (birinin bir şey) göz/gözünü bağlamak, göz/gözünü boyamak, gözü kapalı evlenmek deyimleri düşünmeyi ve duyguları yanıltmayı ve kişiyi kandırmayı ifade etmekte ve görmenin engellenmesinin doğru düşünmenin engellenmesi olarak kavramsallaştığını göstermekte ve MANTIKLI DÜŞÜNMEK GÖRMEKTİR eğretilemesini doğurmaktadır. 


\subsection{Duyguların Kavramsallaştırılmasında Göz}

Bulgular, 'göz'ün duygu ifadelerinde sıklıkla kullanıldığını ve duygusal durumların en belirgin göstergeleri olduğunu ortaya koymaktadır. Göz sözcüğü, veri tabanında 20 farklı duygu türünün ifadesinde kullanılıp DUYGULARIN YUVASI ve DUYGULARIN YANSITICISI olarak kavramsallaşmaktadır. 'Gözler kalbin aynasıdır' ifadesinde olduğu gibi, kişi hissettiği gerçek duyguları gözlerinden saklayamaz ve bu duyguları gözleri vasıtasıyla yalansız ve olduğu gibi karşı tarafa aktarır. Duygu türleri, deyim örnekleri ile birlikte aşağıdaki tabloda alfabetik sıraya göre sunulmuştur:

Tablo 1. Duygu türleri ve örnek deyimler

\begin{tabular}{|c|c|c|}
\hline 1 & Arzu & gözleriyle yemek, göz koymak \\
\hline 2 & Cesaret & gözü kara çıkmak, gözü pek \\
\hline 3 & Duygulanma & gözleri dolmak, gözleri yaşarmak \\
\hline 4 & Duygusuzluk & $\begin{array}{l}\text { gözünün yaşına bakmamak, } \\
\text { göz kırpmadan }\end{array}$ \\
\hline 5 & Güven & gözü tutmak, gözü kesmek \\
\hline 6 & Hayal Kırıklığı & gözü açık gitmek, gözünde kalmak \\
\hline 7 & Hayranlık & göz kamaştırıcı, gözünü alamamak \\
\hline 8 & Hayret & $\begin{array}{l}\text { gözlerine inanamamak, } \\
\text { gözleri fal taşı gibi açılmak }\end{array}$ \\
\hline 9 & Kıskançlık & göze diken olmak, kem gözle bakmak \\
\hline 10 & Korku & gözü korkmak, gözü arkada kalmak \\
\hline 11 & Nefret/Hoşlanmama & gözü görmez olmak, gözden düşmek \\
\hline 12 & Öfke & gözü kızmak, gözünü kan bürümek \\
\hline 13 & Özlem & gözünde tütmek, gözü yollarda kalmak \\
\hline 14 & Rahatlama & gözü gönlü açılmak \\
\hline 15 & Sevgi/Hoşlanma & iki gözüm, göz bebeğim, göze girmek \\
\hline 16 & Sevinç & gözleri parlamak, gözlerinin içi gülmek \\
\hline 17 & S1kıntı & $\begin{array}{l}\text { gözü çıkmak, } \\
\text { dünya gözüne zindan }\end{array}$ \\
\hline 18 & Umut & (birinin) gözünün içine bakmak \\
\hline 19 & Utanma & gözlerinin içine kadar kızarmak \\
\hline 20 & Üzüntü & $\begin{array}{l}\text { gözleri buğulanmak, } \\
\text { gözünü duman bürümek }\end{array}$ \\
\hline
\end{tabular}

Kövecses (1990; 2000)'e göre eğretileme ve düzdeğişmece, duygu kavramlarını oluşturan iki önemli kaynaktır. Göz sözcüğ̈̈ farklı duygu türlerinin ifadelerinde farklı şekillerde kavramsallaşmakla birlikte duyguların nasıl kavramsallaştığı hakkında da bilgiler vermektedir. 'Göz'ün her bir duygu 
türü ile olan ilişkisinin daha detaylı incelenmesi başka bir çalışmanın konusunu oluşturmaktadır. Bu çalışmada, duygular ve 'göz' ilişkisini yansıtan üst eğretileme ve düzdeğişmeceler altı grupta toplanıp açıklanmıştır.

\subsubsection{DUYGULAR GÖZÜN IÇ்INDEDİR}

BEDEN DUYGULAR İÇİN BİR KAPTIR (Kövecses, 1990) eğretilemesi, bedenin çeşitli bölümlerinin de duyguları içeren bir kap olarak kavramsallaştığını gerektirir. Gözlerinin içi gülmek, gözünde kalmak, göz doldurmak, vs. gibi deyimler çeşitli duyguların gözlerin içinde yer aldığını ve 'göz' vasıtasıyla dışarı yansıtıldı̆̆ını göstermektedir.

'Göz' ile sevilen, hoşa giden ve değer verilen nesneler arasında kurulan eşleşme, göze girmek, gözden çıkmak/çıkarmak, gözden düşmek/düşürmek, gözünde olmamak, gözü olmamak, gözü dünyayı görmemek, gözü görmez olmak, gözden trak tutmak deyimlerinde dile yansımaktadır. Bu deyimlerde, İÇINDE/DIŞINDA imge şemasının bir izdüşümü olarak SEVİLEN/DEĞER VERILEN ŞEY GÖZÜN İÇİNDEDİR ve GÖZ (DEĞERLİ) NESNELER İÇİN BİR KAPTIR varlık eğretilemeleri ortaya çıkmaktadır. Ayrıca, sevilmeyen ve değersiz kabul edilen şeylerin gözden uzak tutulması yani görülmemesi, DEĞER VERME YERINE GÖZ ve DEĞER VERMEK GÖRMEKTİR olarak kavramsallaşmaktadır.

Arzulu bakışlar, görülen bir şeye sahip olma isteği veya görmekle elde edilen sahiplik hakk1, gözü olmak, göz koymak, göz dikmek, gözü doymak, göz(ünü) doyurmak, gözü kalmak, gözünde kalmamak, göz hakkl, göz kirası ifadelerinde ARZULAMAK GÖRMEKTİR ve GÖRMEK ELDE ETMEKTİR alt eğretilemelerini doğurmaktadır.

Kişinin bir konuda birisine veya kendisine güvenmesini ifade eden gözü tutmak/tutmamak, gözü su içmemek, gözü kesmek/kesmemek, korku ifade eden gözü korkmak, gözü arkada kalmak, gözünü yıldırmak deyimlerinde yoğun istek, beğeni, güven, korku ve arzu ilk olarak gözde hissedilen duygular olarak düşünülmekte ve düzdeğişmecesel PARÇA-BÜTÜN ilişkisinin izdüşümü olarak 'göz', kişinin yerine geçmekte ve CANLI BİR VARLIK olarak kavramsallaşmaktadır.

\subsubsection{DUYGULAR DOĞRU ALGILAMAYA ENGELDIRR}

Gözünü kin bürümek, gözü (hiçbir şey) görmemek, gözü dönmek, gözünü kan bürümek, dünya gözüne zindan olmak, gözünü duman bürümek deyimlerinde nefret, öfke, sıkıntı ve üzüntü gibi olumsuz duygular ve gözünü aşk bürümek, gözleri kararmak, gözü bağlı olmak gibi şiddetli bir şekilde hissedilen aşk, arzu ve hayranlık duyguları, gözlerin görmesini, dolayısıyla kişinin doğru düşünmesini ve davranmasını engelleyen bir ÖRTÜ olarak 
kavramsallaşmaktadır. Ayrıca, göz kamaştırıcı/kamaştırmak, göz alıcı/almak gibi hayranlık ifadelerinde hayran olunan kişinin/nesnenin yoğun 1şık saçan bir nesne ile eşleştirilmesinden ötürü gözlerin o nesneyi veya etrafindaki diğer nesneleri iyi görememesi HAYRAN OLUNAN NESNE PARLAK BİR NESNEDİR alt eğretilemesini doğurmaktadır.

\subsubsection{DUYGU ATEŞTIR}

Ateş eğretilemesi öfke ifadelerinde gözü kızmak, gözleri çakmak çakmak olmak, gözlerinde şimşekler çakmak, gözü dumanlanmak deyimleri ile karşımıza çıkmaktadır. Bu deyimlerde öfkeli bakışlar ateşle eşleştirilmekte, 'göz', duyguları karşı tarafa yansıtan bir ayna veya projektör görevi görmektedir. Öfke, bu deyimlerde 'göz'ün 1sısını artırmakta, görüşü engellemekte ve dışarıya kıvılcım veya elektriksel bir güç olarak yansımaktadır.

\subsubsection{DUYGU FIZIKSEL BIR ACIDIR / HASARDIR / TEMASTIR}

Gözü üstünde kalmak, gözü değmek deyimleri k1skançl1k ile fiziksel bir temas arasında bir bağ kurmakta ve KISKANÇLIK FİİKSEL BİR TEMASTIR alt eğretilemesini doğurmaktadır. Sıkıntı ifadelerinde kullanılan gözü çıkmak, gözüne diken olmak, gözlerindeki yaşı kanla silmek, gözüne batmak deyimlerinde olumsuz bir duygu olan sıkıntı ve bu duygunun sebebi kişinin gözüne zarar veren bir durum olarak algilanmaktadır.

\subsubsection{DUYGU NESNESİ DE $\breve{G E R L I ̇ ~ B I R ~ V A R L I K T I R ~}$}

Hassas ve değerli bir organ olarak 'göz', sevgi ve kıskançlık duygularının ifadelerinde gözüm, iki gözüm, (ilk) göz ă̆rlsl, göz bebeğim, gözünün bebeği gibi sevmek/bakmak, (să̆ gözünü sol) gözünden sakınmak, gözünden kıskanmak deyimlerinde sevilen ve kıskanılan kişinin yerine konmaktadır. $\mathrm{Bu}$ kavramsal eşleşme DUYGU NESNESİ DEĞERLİ BİR VARLIKTIR ve SEVILEN İNSAN/NESNE GÖRME ORGANIDIR eğretilemelerini ortaya çıkarmaktadır.

\subsubsection{DUYGU YERINE DUYGUNUN FIZYOLOJIK ETKILERI VE DAVRANIŞSAL TEPKILERI}

Kövecses (2000), duygu düzdeğişmecelerini DUYGU YERİNE DUYGUNUN SEBEBİ (CAUSE OF THE EMOTION FOR THE EMOTION) ve DUYGU YERINE DUYGUNUN ETKISII (EFFECT OF THE EMOTION FOR THE 
EMOTION) olarak iki genel başlık altında toplar ve ikinci düzdeğişmecenin ilkinden daha yaygın olduğunu belirtir. DUYGU YERINE DUYGUNUN ETKİSI düzdeğişmecesi, belirli duygularla ilişkilendirilen fizyolojik, davranışsal ve ifadesel tepkileri içeren alt düzdeğişmecelerden oluşmaktadır (Kövecses, 2000). Bulgular, duygu kavramlarının sıklıkla bu alt düzdeğişmeceler ile betimlendiğini göstermektedir.

Duygu yerine duygunun fizyolojik etkileri düzdeğişmecesi altında, hayret ve korku yerine göz kapaklarının açılmasıyla gözlerin dışarıya çıkmasını ifade eden gözleri fal taşı gibi açılmak, gözleri yuvalarından firlamak, gözleri fildır fildır olmak, öfke ve utanç yerine gözlerin kızarmasını ifade eden gözleri kan çanağına dönmek, gözlerinin içine kadar kızarmak deyimleri listelenebilir.

Duygu yerine duygunun davranışsal tepkileri, üzüntü ve duygulanma yerine gözlerin yaşarması ve ağlama ifade eden gözleri nemlenmek, gözünden yaşlar boşanmak, gözleri bulutlanmak, gözleri dolmak, göz yaşartıcı, arzu, sevgi, hayranlık ve özlem yerine uzun süreli bakışları ifade eden gözüyle yemek, gözünün içine bakmak, (bir şeyden) gözünü ayırmamak, gözünü alamamak, gözü yollarda kalmak, öfke yerine dik ve sert bakışlar ve saldırgan davranışlarda bulunma ifade eden kaşını gözünü ĕgmek, gözlerini devirmek, gözünü oymak/çıkarmak olarak sıralanabilir.

\subsection{Karakter Özelliklerinin Kavramsallaştırılmasında 'Göz'}

'Göz' deyimleri hırs, kanaatkârlık, kurnazlık ve saflık gibi birbiriyle zıt anlamsal bir ilişki içindeki kişilik özellikleriyle ilişkilendirilmiştir. Sonu gelmeyen istek ve aşırı tutku olarak tanımlanan hırs, olumsuz bir karakter özelliğidir. Gözünü hırs bürümek deyiminde aşırı hırs gözü kaplayan böylece görme yetisini engelleyen bir örtü olarak kavramsallaşmaktadır. Gözü yükseklerde olmak deyiminde kişinin bulunduğu konumdan daha yükseğini ve sahip olduklarından daha fazlasını istemesi FAZLA OLAN YUKARDADIR eğretilemesiyle bağlantılı olarak kişinin gözleriyle yukarı bakması olarak yorumlanmaktadir.

Kişinin sahip olduklarıyla yetinmemesi ve daha fazlasını istemesiyle ilişkili ruhsal açlık, gözü aç (olmak) deyiminde görme organındaki açlık olarak yorumlanmakta ve gördüğü her şeye sahip olmayı isteme olarak yorumlanabilir. Diğer taraftan, kanaatkârlık, kişinin az olanla yetinmesi olarak tanımlanır. Kişinin kanaatkâr olması ve sahip olduklarıyla yetinmesi tok gözlü, gözü (gönlü) tok deyimlerinde fiziksel toklukla eşleşmiş ve kişinin gözünün tokluğu olarak kavramsallaşmıştır. Deyimlerde BÜTÜN YERİNE PARÇA düzdeğişmecesinden yola çıkılarak kişinin gözü ile kendisi arasında bir bağ kurulmakta ve 'göz' kişiyi temsil etmektedir.

Veri tabanındaki kurnazlık ifade eden açık göz, açık gözlük etmek, gözü açık (olmak), gözleri velfecir okumak deyimleri kişinin becerikli ve uyanık olmasını 
ve firsatlardan yararlanmasını bilmesini gözlerin açıklığ iliş̧kilendirmektedir. Diğer taraftan, gözü kapalı (olmak) deyimi kişinin çevresinde olup bitenden haberdar olmamasını, saflık ve ilgisizliği ifade etmektedir. Bu sebeple saflık ve ilgisizlik gözü tamamen kapatarak algılamayı ve kişinin gerçekleri görmesini engelleyen bir bağ olarak algılanmaktadır. Deyimleri BÜTÜN YERİNE PARÇA düzdeğişmecesinin alt türü olan KİşI YERINNE GÖZ motive etmektedir.

\subsection{Fiziksel Durumların Kavramsallaştırılmasında 'Göz'}

Uyku, ölüm, yaşam ve zamanın akışı, göz deyimlerinde ifade edilen fiziksel durumlar olarak karşımıza çıkmaktadır. Doğum ve yaşam ifadelerinde kullanılan göz açmak ve dünya gözüyle (görmek) ve ölüm ifadelerinde kullanılan (dünyaya) gözlerini kapamak, (hayata) gözlerini yummak, gözleri bütün yumulası, gözü açık gitmek, gözü topră̆a bakmak deyimlerinde 'göz'ün bedenin tamamının yerine geçtiği BÜTÜN YERİNE PARÇA düzdeğişmecesi gözlenmektedir. Deyimlerde ölen kişinin genellikle gözlerinin kapalı olması ile uyuyan kişinin gözlerinin kapalı olması arasında deneyimsel bağ kurulmakta, böylece ölüm örtmece yöntemiyle daha üstü kapalı bir şekilde ifade edilmektedir.

Göz kırpmamak, gözleri süzülmek, gözünden uyku akmak, gözüne uyku girmemek, gözleri baylmak deyimlerinde UYKUNUN GÖZLER ÜZERİNDEKİ FİZYOLOJIKK ETKİLERİ uykunun yerine geçmektedir.

Göz açıp kapayıncaya kadar (kapamadan), göz kırpıncaya kadar, gözle kaş arasında deyimleri, soyut zaman kavramını ve bu kavramın ölçümünü görsel bir alg1 vasitasıyla anlamlandırmakta ve KISA ZAMAN SÜRECİ YERINE GÖZ / GÖZ KIRPMA kavramsal düzdeğişmecesini oluşturmaktadır. Bu kategorideki değişmeceli ifadelerden de anlaşıldığı gibi, 'göz' bir alg1 vasıtası olarak, fiziksel durumlarla ilgili deneyimlerimizde önemli bir algisal referans noktası oluşturmaktadır.

\subsection{Kültürel Ögelerin Kavramsallaştırılmasında 'Göz'}

Kültürel ögeler başlığı altında nazar, iyi dilek, ilenç ve yemin etme ifadelerini içeren göz deyimlerine rastlanmaktadır. Türk kültüründe, kıskanç veya hayran bakışların kişiler veya nesneler üzerinde zarar verici olumsuz bir gücü olduğu inanılır. Nazar olarak adlandırılan bu vurucu kuvvet, 'ruhun dışa açılan iki noktasından yani gözden fışkırarak kurbanına isabet etmektedir' (Koca, 2012, s. 183). Bu sebeple halk dilinde nazar sözcüğü s1klıkla göz sözcüğü yerine kullanılır (örn. nazara gelmek, nazara uğramak, nazar değmesi, nazar etmek). "Göze gözle" karş1 koymak düşüncesinden yola çıkılarak nazara karş1 
korunmak ve nazarı uzaklaştırmak için kullanılan objeler çoğunlukla göz şeklindedir (Koca, 2012, s. 183). Veri tabanında bulunan göz boncuğu, ak gözlü, göz(ü) değmek, göze gelmek, kem gözle bakmak deyimleri göz organının nazarı kavramsallaşıtımada kullanıldığını ve NAZAR YERİNE GÖZ, GÖZ NAZARIN ÇIKIŞ KAYNAĞIDIR ve GÖRMEK DOKUNMAKTIR olarak kodlandığını göstermektedir.

Güzel olayları kutlamak, bir kişinin sevinçli bir durumuna ortak olmak, iyi dilek ve temenni ifadelerinde sıklıkla kullanılan gözün aydın, göz aydın etmek, göz aydına gitmek deyimleriyle kişinin gözünde parlaklık ve 1ş1ltı dilenmesi, Lakoff, Espenson ve Schwartz'ın (1991) temel eğretileme listesinde yer alan IYYI OLAN ŞEYLER AYDINLIKTIR / KÖTÜ OLAN ŞEYLER KARANLIKTIR (GOODNESS IS LIGHT / BADNESS IS DARKNESS) eğretilemesi ile paralellik göstermektedir.

Diğer yandan, göz sözcüğü kötü dilek olarak da tanımlanan ilenç ifadelerinde de karşımıza çıkmakta ve gözleri akası, gözüne dizine dursun, gözünü toprak doyursun, gözü kör olsun, gözleri bütün yumulası deyimlerinde sevilmeyen ve beddua edilen kişinin kıymetli bir organı olarak gözüne zarar gelmesini dilemek olarak dişa vurulmaktadır. GÖZ DEĞERLİ BİR NESNEDİR ve KISŞI YERİNE GÖZ / BÜTÜN YERINNE PARÇA bu ifadelerin altında yatan kavramsal mekanizmalardır.

Benzer bir şekilde, gözüm çılksı, gözüm kör olsun ve iki gözüm önüme aksın gibi yemin etme ve ant içme ifadelerinde karşıdaki kişiyi bir şeyin doğruluğuna inandırmak için kişinin sözlerinin doğru olmadığı durumda kendi gözüne zarar gelmesini ve görme yetisini kaybetmesini dilemesinin altında GÖZ DEĞERLİ BİR NESNEDİR eğretilemesi yatmaktadır.

\section{Bulgular ve Tartışma}

Gözler insanların kimliklerini oluşturan önemli fiziksel özelliklerdir. Yu'nun (2001, 2004) da vurguladığı gibi, yüz, fiziksel ve sosyal yönden insanların en belirgin beden bölümü olarak düşünülse de, odak noktası gözler üzerindedir. Yapılan inceleme, gözlerimizle algısal bir organ olarak neler yaptığımızın ve kim olduğumuzun Türkçe deyimlere açıkça yansıdığını ortaya koymaktadır. Göz ve çevresindeki mimikler, gözlerdeki hareketlilik, bakma süresi, nereye baktığımız ve gözle ilişkilendirilen kültürel kavramlar, duygularımızın, karakter özelliklerimizin, zihinsel işlemlerimizin, fiziksel durumlarımızın, davranışlarımızın ve tepkilerimizin ifade edilişinde önemli bir yere sahiptir ve sosyo-kültürel bilişin inşasında önemli bir rol oynamaktadır.

Yapılan analizler gözün zihinsel yetiler, duygular, karakter özellikleri, fiziksel durumlar ve kültürel değerlerin değişmeceli ifadelerinde önemli bir kaynak alan olduğunu ve eğretilemeler, düzdeğişmeceler ve imge șemalarıyla beraber cisimleşmiş kültürel bir model oluşturduğunu göstermektedir. Bu 
kültürel ve bilişsel model içinde 'göz', görme organı olarak yerine getirdiği temel işlev dişında, bu işleve dayanarak çeşitli roller üstlenmektedir: insanlarla iletişim kurmayı sağlayan bir araç, duyguların yuvası, duygu, düşünce, hafıza ve niyetlerin bulunduğu bir kap ve yansıtıldığı bir ayna, değerli bir beden bölümü, algısal referans noktası, dış dünyaya ait bilgilerin edinildiği bir kaynak, yönlendirilebilir bir nesne, canlı bir varlık gibi. Göz deyimlerinden elde edilen bulgulardan yola çıkılarak 'göz'e ait oluşturulan bilişsel model aşağıdaki şekilde sunulmaktadır:

Şekil 3. Göz kültürel-bilişsel modeli

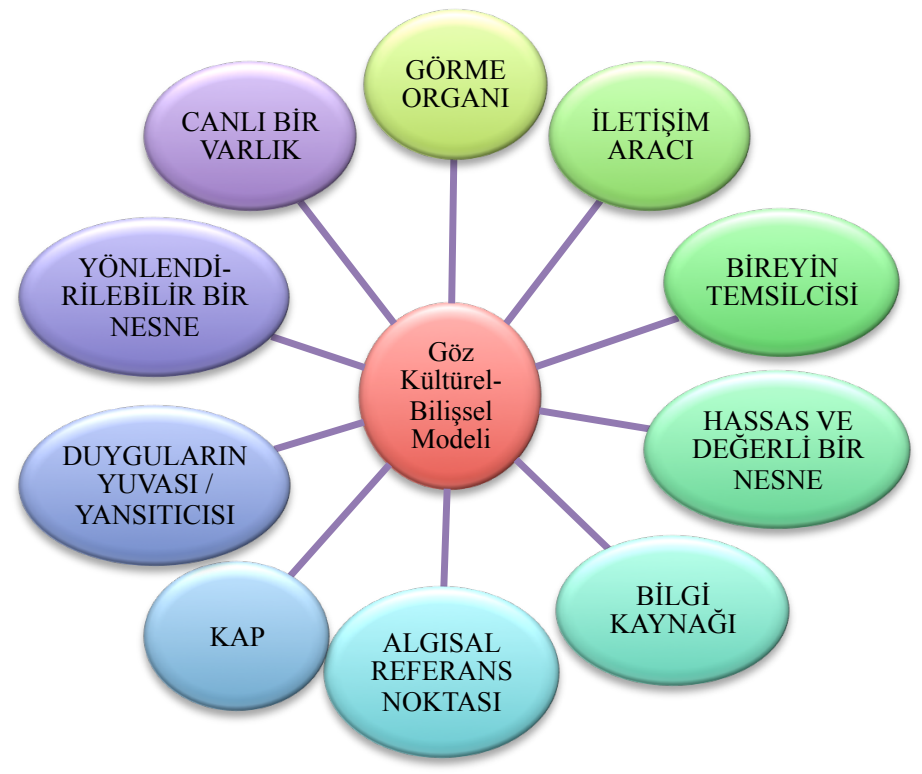

Elde edilen bulgular diğer dillerdeki çalışmalarla bazı benzerlikler ve farklılıklar ortaya koymaktadır. İngilizce (Barcelona, 1997; Sweetser, 1990), Çince (Yu, 2002, 2003, 2004), Japonca (Occhi, 2011), Farsça (Sharifian, 2011) ve Arapçada (Maalej, 2011) olduğu gibi Türkçede de düşünme, kontrol, dikkat, değerlendirme gibi zihinsel yetiler fiziksel bir deneyim olan görme algısına dayanmakta ve DÜŞÜNMEK, KONTROL ETMEK, DİKKAT ETMEK, DEĞERLENDİRMEK, KARAR VERMEK GÖRMEKTİR eğretilemelerini içermektedir. $\mathrm{Bu}$ bulgu, farklı dillerin, gözün değişmeceli anlamlarının ifadelerinde gözün işlevi ve yapısının çeşitli yönlerini benzer şekilde kavramsallaştırdığını göstermektedir. Zihinsel işlevlere ait bu ortaklıklar 
'göz'ün, deneyimleyen ve gözlemleyen bir varlık olarak kodlandığını ve bu zihinsel becerilerle doğrudan ilişkilendirildiğini göstermektedir. $\mathrm{Bu}$ durum, BEDEN ZİHINDİR üst eğretilemesinin altında GÖZ ZİHINDİR eğretilemesini ortaya koymaktadır. Dolayısıyla, vücudun bir parçası olarak 'göz', doğrudan zihni temsil etmektedir. Bu bulgu, anlam, tasavvur ve muhakeme açısından zihin ve bedeni birbirinden ayıran zihin-beden ikiciliğine (Cartesian dualism) karşı, bedenleşmiş biliş görüşünün bir uzantısı olarak, bedensel süreçlerin bizim zihin olarak deneyimlediğimiz sinirsel süreçler için vazgeçilmez bir referans çerçevesi oluşturduğunun açık bir ispatıdır (Johnson, 1987; Damasio, 1994).

Duyguların kavramsallaştırılmasında 'göz', Arapça (Sharifian, 2011) ve Farsça (Maalej, 2011) ile benzerlikler göstermektedir. Üç dilde de göz sözcüğü, sevgi, kıskançlık, arzu ve öfke ifadelerinde kaynak alan olarak kullanılmakta ve çeşitli duygu türlerini barındıran bir KAP, duyguları yansıtan bir PROJEKTÖR veya AYNA, duygulardan etkilenen bir NESNE sevilen kişinin yerine geçen DEĞERLİ BİR NESNE olarak görev yapmaktadır. Ayrıca, hırs, kanaatkârlık, kurnazlık, saflık gibi karakter özelliklerinin ve zaman ve ölüm gibi fiziksel durumların kavramsallaştırılmasında 'göz', her üç dilde de benzer roller üstlenmekte ve hemen hemen aynı dilsel ifadelerde kullanılmaktadır. Bu durum Türkçenin bu dillerle uzun yıllar yakın temas halinde olması sonucu dilsel alışverişlere bağlanabilir.

'Göz'ün düzdeğişmecesel anlam genişlemesi, çoğunlukla sinekdot (synecdoche) olarak da adlandırılan parçanın bütünün yerine geçtiği BÜTÜN YERİNE PARÇA (KIŞSI YERİNE GÖZ) ilişsisinden kaynaklanmaktadır ve nispeten daha somut olan bu düzdeğişmeceden, daha soyut olan ZïHİNDE CANLANDIRMA YERİNE GÖZ gibi zihinsel mekanizmaların işleyişine kadar uzanmaktadır. Deneyimsel motivasyona sahip bu düzdeğişmeceler farklı dillerde benzerlikler göstermektedirler. Örneğin, soyut zaman kavramının hızlı göz hareketleri ile ifade edilmesinden doğan KISA ZAMAN SÜRECI YERİNE GÖZ / GÖZ KIRPMA düzdeğişmecesine Farsçada da rastlanmaktadır (Maalej, 2011). Maalej, fizyolojik temelli bu düzdeğişmecelerin "evrensel olma potansiyeline sahip bedenleşmiş bilişin bir türü" olarak adlandırmaktadır (2011, s. 236).

Çalışmanın bulguları, önceki çalışmaların bulgularından bazı açılardan farkl111k göstermektedir. Bahsi geçen çalışmaların aksine, ANLAMAK GÖRMEKTIR ve BILLMEK GÖRMEKTİR eğretilemelerine Türkçe göz deyimlerinde rastlanmamıştır. Ayrıca, 'göz'ün hatırlama, karar verme, değerlendirme, deneyim kazanma, niyet etme yerine geçtiği kullanımlar önceki çalışmalarda belirtilmemiştir. Bu farklılıklar, zihinsel süreçler her ne kadar BEDEN ZIHINDIIR üst eğretilemesine dayansa da, farklı dillerde belirli kavramların ve süreçlerin diğerlerine göre daha fazla ön plana çıktığını ve buna bağlı olarak dilde daha fazla yer ettiğini göstermektedir. İnsan bedeni her ne 
kadar eğretilemelerin ve düzdeğişmecelerin ortaya çıkışında evrensel bir kaynak olsa da, kültürel modeller, eğretilemesel eşleşmelerin ortaya çıkışında duyu-motor deneyimlerin farklı yönlerini seçme ve onları öznel deneyimler ve hükümlerle ilişkilendirme sürecinde filtre görevi görmektedir. Diğer bir ifadeyle, Yu'nun da belirttiği gibi, eğretilemeler kültürel çevre içerisinde vücut bulmaktadır (2008, s. 247). Dil, dış dünyayı doğrudan yansitmamaktadır, aksine insanların kavramsallaştırmalarını ve dünyayı yorumlamalarını yansıtmaktadır (Wierzbicka, 1992, s. 7). Kültürel süreçlerin bedenleşmiş biliş üzerindeki etkisiyle, beden bölümleriyle ilișkilendirilen kavramlar ve bu bölümlere kodlanan derin anlamlar dile özgü özellikler göstermektedir.

\section{Sonuç}

$\mathrm{Bu}$ çalışma, göz sözcüğünün deyimler aracılığıyla nasıl kavramsallaştığını incelemiş ve bu deyimlerin altında yatan çeşitli kavramsal eğretilemeler ve düzdeğişmeceleri ortaya koyarak 'göz'e ait bilişsel ve kültürel bir model önerisinde bulunmuştur. 'Göz' kavramı, Türkçede zihinsel faaliyetlerin, duygusal deneyimlerin, kişilik özeliklerinin, fiziksel durumların ve kültürel ögelerin ifadelerinde önemli bir görev üstlenmektedir. Yapılan inceleme, dil, beden, biliş ve kültür arasındaki yakın ilişkiyi açıkça ortaya koymakta ve kültürel biliş (Sharifian, 2008, 2009, 2011) görüşünü desteklemektedir. Gibbs'in de belirttiği gibi "beden kültürden bağımsız bir nesne değildir çünkü bedenleşmiş deneyimlerin her yönü kültürel süreçler tarafından şekillendirilmektedir" (2006, s. 13). Diğer bir ifadeyle, "insan fizyolojisi aynı olsa bile dillerin bedensel deneyimleri nasıl yorumlayıp yansıttıkları basit biyolojik açıklamalara karşı çıkan kültürel pratikler tarafından yönlendirilmektedir" (Gibbs, 2006, s. 13). Dil, kültürel kavramsallaşmalar için bir "hafiza bankası" rolü üstlenmekte (Sharifian, 2012, s. 14) ve insan deneyimlerinin çeşitli yönlerinin kavramsallaştırılmasında kaynak oluşturmaktadır. Dilin bir parçası olan deyimler içinde kodlanan sosyo-bilişsel şemalar, bir kültürel grubun üyelerince paylaşılmakta ve anadili öğrenme sürecinde nesilden nesile aktarılmaktadır.

\section{Kaynaklar}

Barcelona, A. (1997). Clarifying and applying the notions of metaphor and metonymy within cognitive linguistics. Atlantis, 19 (1), 21-48.

Barcelona, A. (2000). Introduction: The cognitive theory of metaphor and metonymy. A. Barcelona (Der.) içinde, Metaphor and Metonymy at the Crossroads: A Cognitive Perspective (ss. 1-28). Berlin: Mouton de Gruyter.

Barcelona, A. (2003). On the plausibility of claiming a metonymic motivation for conceptual metaphor. A. Barcelona (Der.) içinde, Metaphor and Metonymy at the 
Crossroads: A Cognitive Perspective (ss. 31-58). Berlin: Mouton de Gruyter.

Barcelona, A. (2011). Reviewing the properties and prototype structure of metonymy. R. Benczes, A. Barcelona ve R. de Mendoza Ibanez (Der.) içinde, Defining metonymy in cognitive linguistics (ss. 7-57). Amsterdam /Philadelphia: John Benjamins Publishing Company.

Baş, M. (2015). Conceptualization of Emotion through Body Part Emotions in Turkish: A Cognitive Linguistic Study. Yayınlanmamış Doktora Tezi, Hacettepe Üniversitesi, Ankara.

Damasio, A. R. (1994). Descartes'ın Yanılgısl: Duygu, Akıl ve İnsan Beyni. İstanbul: Varlık Yayınları.

Evans, V. ve Green, M. (2006). Cognitive Linguistics: An Introduction. Edinburgh: Edinburgh University Press.

Gibbs, R. W. (2006). Embodiment and Cognitive Science. Cambridge: Cambridge University Press.

Goossens, L. (1995). Metaphtonymy: The interaction of metaphor and metonymy in expressions for linguistic action. L. Goossens, P. Pauwels, B. Rudzka-Ostyn, A. Simon-Vanderbergen, ve J. Vanparys (Der.) içinde, By word of mouth: Metaphor, Metonymy and Linguistic Action in a Cognitive Perspective (ss. 159-174). Amsterdam/Philadelphia: John Benjamins.

Johnson, M. (1987). The Body in the Mind: The Bodily Basis of Meaning, Imagination, and Reason. Chicago/London: The University of Chicago Press.

Koca, S. K. (2012). Türk Kültüründe Sembollerin Dili. Yayınlanmamış Doktora Tezi, Sakarya Üniversitesi, Sakarya.

Kövecses, Z. (1990). Emotion Concepts. New York: Springer.

Kövecses, Z. (2000). Metaphor and Emotion: Language, Culture, and Body in Human Feeling. Cambridge: Cambridge University Press.

Kövecses, Z. (2010). Metaphor: A Practical Introduction (2. Basım). New York: Oxford University Press.

Kövecses, Z. ve Radden, G. (1998). Metonymy: Developing a cognitive Linguistic view. Cognitive Linguistics, 9, 37-77.

Lakoff, G., Espenson, J. ve Schwarts, A. (1991). Second draft copy: Master metaphor list. [http://araw.mede.uic.edu/ alansz/metaphor/METAPHORLIST.pdf. Erişim tarihi Haziran 20, 2012].

Lakoff, G. ve Johnson, M. (1980). Metaphors We Live By. Chicago: The University of Chicago Press.

Lakoff, G. ve Johnson, M. (1999). Philosophy in the Flesh: The Embodied Mind and Its Challenge to Western Thought. New York: Basic Books.

Maalej, Z. A. (2011). Figurative dimensions of 3ayn 'eye' in Tunisian Arabic. Z. Maalej ve N. Yu (Der.) içinde, Embodiment via Body Parts: Studies from Various Languages and Cultures (ss. 213-240). Amsterdam/Philadelphia: John Benjamins Publishing Company.

Maalej, Z. ve Yu, N. (Der.). (2011). Embodiment via Body Parts: Studies from Various Languages and Cultures. Amsterdam/Philadelphia: John Benjamins Publishing Company.

Occhi, D. J. (2011). A cultural-linguistic look at Japanese 'eye' expressions. Z. Maalej ve N. Yu (Der.) içinde, Embodiment via Body Parts: Studies from Various Languages and Cultures (ss. 171-191). Amsterdam/Philadelphia: John Benjamins Publishing Company.

Panther, K. ve Radden, G. (1999), (Eds.). Metonymy in Language and Thought. Amsterdam: John Benjamins.

Radden, G. (1996). Motion metaphorized: The case of coming and going. E. H. Casad 
(Der.) içinde, Cognitive Linguistics in the Redwoods: The Expansion of a New Paradigm in Linguistics (ss. 423-458). Berlin: Mouton de Gruyter.

Sharifian, F. (2008). Distributed, emergent cultural cognition, conceptualisation, and language. R. M. Frank, R. Dirven, T. Ziemke ve E. Bernandez (Der.) içinde, Body, Language, and Mind (Vol. 2): Sociocultural Situatedness (ss. 109-136). Berlin/New York: Mouton de Gruyter.

Sharifian, F. (2009). On collective cognition and language. H. Pishwa (Der.) içinde, Language and social cognition (ss. 163-182). Berlin/New York: Mouton de Gruyter.

Sharifian, F. (2011). Conceptualizations of cheshm 'eye' in Persian. Z. Maalej ve N. Yu (Der.) içinde, Embodiment via Body Parts: Studies from Various Languages and Cultures (ss. 197-211). Amsterdam/Philadelphia: John Benjamins Publishing Company.

Sharifian, F. (2012). Translation and body-part terms: The case of cheshm 'eye' in Persian. Journal of Language, Culture, and Translation (LCT), 1(1), 1-16.

Sharifian, F., Dirven, R., Yu, N. ve Niemeier, S. (Der.). (2008). Culture, Body, and Language: Conceptualizations of Internal Body Organs across Cultures and Languages. Berlin: Mouton de Gruyter.

Siahaan, P. (2011). Head and eye in German and Indonesian figurative uses. Z. Maalej ve N. Yu (Der.) içinde, Embodiment via Body Parts: Studies from Various Languages and Cultures (ss. 93-113). Amsterdam/Philadelphia: John Benjamins Publishing Company.

Sweetser, E. (1990). From Etymology to Pragmatics: Metaphorical and Cultural aspects of Semantic Structure. Cambridge: Cambridge University Press.

Wierzbicka, A. (1992). Semantics, Culture, and Cognition: Universal Human Concepts in Culture-Specific Configurations. New York/Oxford: Oxford University Press.

Yu, N. (2001). What does our face mean to us? Pragmatics and Cognition 9, 1-36.

$\mathrm{Yu}, \mathrm{N}$. (2002). Body and emotion: Body parts in Chinese expression of emotion. Pragmatics and Cognition 10, 341-367.

Yu, N. (2003). Chinese metaphors of thinking. Cognitive Linguistics, 14(2-3), 141-165.

$\mathrm{Yu}, \mathrm{N}$. (2004). The eyes for sight and mind. Journal of Pragmatics, 36, 663-686.

$\mathrm{Yu}$, N. (2008). Metaphor from body and culture. R. W. Gibbs (Der.) içinde, The Cambridge Handbook of Metaphor and Thought (ss. 242-262). Cambridge: Cambridge University Press. 